Ecology, 99(3), 2018, pp. 755-757

(C) 2017 by the Ecological Society of America

\section{First record on stranding of a live giant squid Architeuthis dux outside Japanese waters}

After much discussion on the number of species of giant squid (Guerra et al. 2006), Winkelmann et al. (2013) showed that mitochondrial DNA lacks phylogenetic structure and that nucleotide diversity is exceptionally low, suggesting either a recent population expansion or a selective sweep. These observations are consistent with the existence of a single species of giant squid, Architeuthis dux Steenstrup, 1857, and suggest that it is highly vagile, possibly dispersing through both a drifting larval stage and migration of larger individuals.

Historically, records of this elusive mesopelagic species are concentrated in five regions: (1) from Newfoundland to the Gulf of Mexico; (2) Northeast Atlantic waters, at present mostly in Northern Spain; (3) Namibia and South Africa; (4) Japan; and (5) New Zealand and Southeastern Australia (Guerra et al. 2006, Roper et al. 2015, Kubodera et al. 2016). Common features of these regions are the presence of submarine canyons near the continental shelf, high productivity, mainly produced by the upwelling of cold water $\left(4^{\circ}-6^{\circ} \mathrm{C}\right)$, existence of large predators, closeness of bays that retain carcasses, and inhabited coastal areas that allow their detection (Guerra et al. 2005). The areas with the highest number of sightings in the last three decades are the Sea of Japan and the northern coasts of Spain (Guerra and Segonzac 2014, Kubodera et al. 2016). The wide geographical spread of these records together with the genetic structure of the $A$. dux populations leads to the conclusion that it is a cosmopolitan species. This wide geographical distribution suggests wide dispersion of its larval stages, which could be favored by the thermohaline conveyor belt (Winkelmann et al. 2013).

Sixty records of strandings of $A$. $d u x$ in Northern Spain were registered from 1962 to 2016, i.e., approximately one individual per year. However, in autumn of both 2001 and 2003, several large animals (four and five, respectively) with acute tissue damage stranded over a two-week period. It has been suggested that these deaths were caused by acoustic impacts of seismic prospection (Guerra et al. 2004). The strandings were scattered along the coast, and all originated from a large fishing ground, which crosses the Llanes, Lastres, Avilés, and Ribadeo submarine canyons (Guerra et al. 2006, 2009). However, no paralarvae or juveniles have been found and it is unknown whether $A$. $d u x$ is present in the area over its entire life cycle.

Although there are records of live giant squids in Japan (McKirdy and Ogura 2015, Kubodera et al. 2016), there are no previous records of live specimens in Northern Spain.

Architeuthis dux is one of the largest invertebrates known. Although little is known about its biology and ecology, the study of the gut contents of several stranded specimens from various parts of the world has permitted inferences about its trophic level and the composition of

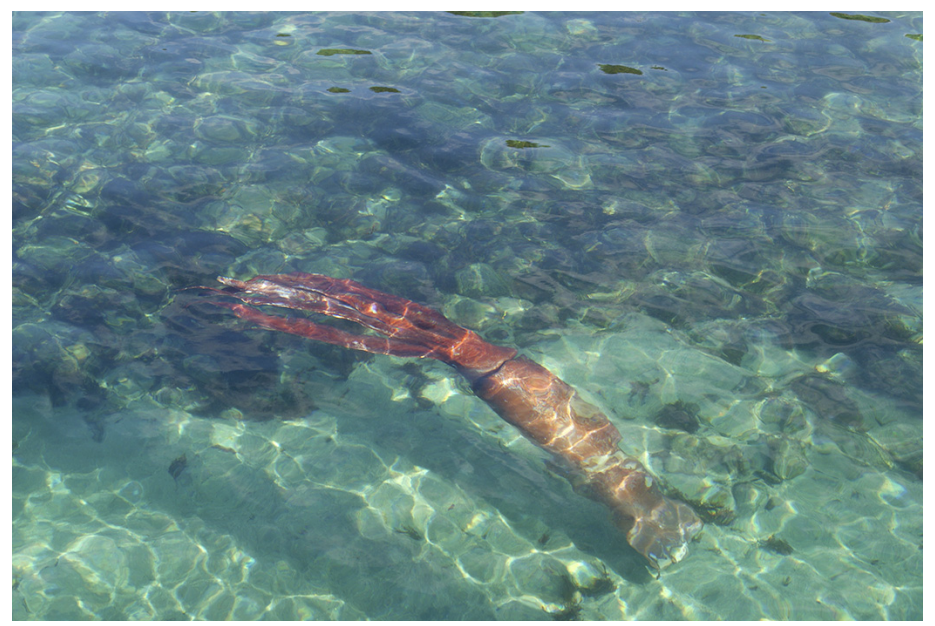

FIG. 1. Live Architeuthis dux photographed close to the wharf at Bares, northwest Spain. 
its diet. Regueira et al. (2014) showed that $A$. dux preys mainly on pelagic shoaling fishes and cephalopods, and that one of the most frequent prey items in northern Spanish waters is the blue whiting (Micromesistius poutasou). Blue whiting is a mesopelagic fish, found at $150-3,000 \mathrm{~m}$ depth, usually at $300-400 \mathrm{~m}$. It forms dense shoals and has high commercial value (Cohen et al. 1990). The species is fished in northern Spanish waters by pair trawlers, between 250 and $600 \mathrm{~m}$, especially in later summer and autumn. Juvenile blue whiting are found on the coastal fishing grounds where warm water currents carry the larvae and juveniles from the spawning areas, and where upwelling in spring-summer enables abundant food stocks. The peak abundance of blue whiting coincides with the highest number of A. dux strandings (Guerra et al. 2006, Guerra and Segonzac 2014).

On 7 October 2016, we were informed that the carcass of a giant squid had stranded on Bares beach $\left(43^{\circ} 46.17^{\prime} \mathrm{N}, 7^{\circ} 40.25^{\prime} \mathrm{W}\right)$. Its necropsy showed that (1) it was a very fresh immature female (with no signs of mating) of $105 \mathrm{~kg}$ and $123 \mathrm{~cm}$ dorsal mantle length; (2) both tentacles were cut at the base; (3) no food remains were found in the digestive tract; (4) there were no traces of macroscopic parasites; (5) it showed numerous sucker marks (diameter $2.14-4.60 \mathrm{~cm}$ ) and scrapes on the skin (Fig. 1); (6) the teeth of the sucker rings were short and of a similar size; and (7) the specimen had a long $(24 \mathrm{~cm})$ and deep wound in the right side of mantle. Photos (Fig. 2) were taken before the stranding, while the animal was still alive, floating a few meters from the wharf of the port at about $3 \mathrm{~m}$ depth. Two and a half hours after the first observations, it stranded on the beach. Subsequent molecular analyses (mtDNA) revealed it to be $A$. dux.

Based on a beached specimen with sucker scars on its mantle and arms $(2.7-4.0 \mathrm{~cm}$ diameter), and serrations

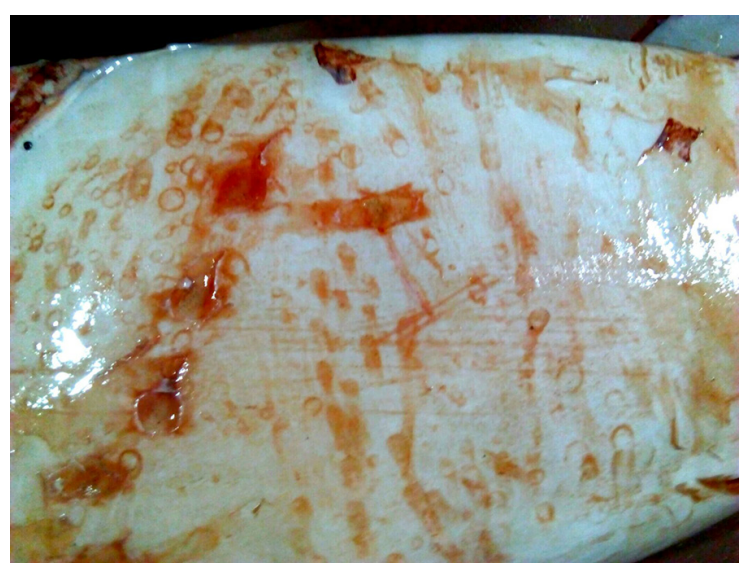

FIG. 2. Sucker marks and scars on the skin of the mantle of the $A$. dux specimen. on some arms inconsistent with damage caused by beaching, Aldrich (1991) attributed these injuries to combat with a conspecific. Sucker scars on the Bares specimen have comparable diameter to those reported by Aldrich (1991), suggesting a similar battle, apparently with another large cephalopod. The beak of the other animal might have produced the deep scratches in the skin. The deep wound in the side of the animal is compatible with a collision with the stones of the Bares beach protection wall.

We suggest four hypotheses to explain the evidence of fighting: (1) defending a territory for mating, (2) cannibalism, (3) attack by another large cephalopod, and (4) competition for food (or kleptoparasitism).

The victim was an immature unmated female, which seems to exclude competition for mates. Cannibalism is also unlikely due to the absence of large bite marks. The only other cephalopod species in the area of sufficient size to fight a squid as big as the Bares specimen are Ommastrephes bartramii or Taningia danae. However, the shape of the sucker rings of $O$. bartramii is not consistent with the marks observed in the skin of the Bares specimen and in $T$. danae the suckers are transformed into hooks. Therefore, we suggest that the Bares specimen was engaged in battle with a conspecific. Although interpretation of sucker marks is subject to biases due to suction pressure, and the relationship between body mass and the diameter of the largest suckers on the tentacular clubs in $A . d u x$ is highly variable, the attacker was probably considerably larger. Thus, two females weighing 135 and $157 \mathrm{~kg}$, respectively, stranded on the north coast of Spain had suckers between 2.15 and $2.40 \mathrm{~cm}$ in diameter to (A. Guerra, unpublished data).

We hypothesize that the these wounds are the result of kleptoparasitism in the following way. When giant squids, which live in the deep and dark submarine canyons, notice the presence of the blue whiting schools, they ascend to waters between 250 and $600 \mathrm{~m}$ deep to feed, leading to the presence of several giant squid of varying sizes in the vicinity of the shoal of fish. Although predation by $A$. dux has not been well observed, in principle its hunting strategy could be pursuit or ambush. In the case of predation on a dense fish shoal, we think that the first type of strategy will prevail over the second. The squid probably hunt individually, attacking the shoal from below and using their tentacles, as observed by Kubodera and Mori (2005). A. dux chop their prey into small pieces with their beaks, and then force the pieces down the throat with the radula. To achieve a daily ingestion rate of between $6 \%$ and $10 \%$ of its mass the squid should remain fairly close to the fish school. However, this strategy could involve excessive exposure to predators, mainly marine mammals; it is likely that having caught a fish they would retreat to a greater depth where the protection is greater. When in the vicinity of a fish school, an individual giant squid may encounter other conspecifics 
feeding. Such a scenario could lead to (interference) competition between individuals and might also favor kleptoparasitism (Rothschild and Clay 1952). In either case, the squid would presumably only attack and displace smaller individuals, so as to minimize the risk to itself, and the latter could be injured during combat. The absence of tentacles, which are easily cut by traction, and the presence of marks on the skin of the Bares squid are consistent with such a scenario. The victim, disoriented and wounded, could enter a warmer mass of water in which the efficiency of their blood decreases markedly (Brix 1983). In this way, the victim, almost asphyxiated, would be at the mercy of the marine currents, being dragged toward the coast.

Food piracy, or kleptoparasitism, occurs across a broad range of taxonomic groups (Barnard 1984), although it has been described only once in cephalopods (Vijai et al. 2017). We hypothesize that kleptoparasitism in the case of $A$. dux is a form of intraspecific aggression involved in food competition, rather than being related to the availability of many hosts feeding on large, high quality, visible food items, or periods of food shortage. Large concentrations of giant squid in the vicinity of a blue whiting shoal are unlikely and it is plausible that it is energetically less costly for a large squid to steal a fish from a smaller squid than to pursue the fish itself, especially if the fish is small relative to the size of the squid (see Domenici 2001), provided that the risk of injury to the larger squid is small. Under these circumstances, kleptoparasitism would increase the net rate of energy intake and potentially reduce the duration of exposure to predators would and thus be favored by natural selection, as proposed by optimal foraging theory (MacArthur and Pianka 1966, Charnov 1976). Given that blue whiting shoals represent a transient source of food, being ephemeral in both space and time, it is very unlikely that such a shoal could be defended and, given that blue whiting can form "enormous shoals" (Nielsen 1994) it is also unlikely that prey availability in the vicinity of such a shoal would be limiting for the squid.

Available information about $A$. $d u x$ is still fragmentary. Kubodera and Mori (2005) published the first photos of a live giant squid in the wild, and the first ever video record of a giant squid in its natural habitat (off Japan) was shown by Discovery Channel (2013). In relation to the proposed behavior of Architeuthis in the vicinity of shoals of fish, observations of feeding by $A$. $d u x$ (and, indeed, other squid species), in the field or in captivity, would be very useful. The successful capture of $A$. $d u x$ larvae using extra-gentle, fine-meshed, plankton net in New Zealand waters (O'Shea 2002) suggests that such experiments with young $A$. $d u x$ are feasible. Studies of this type can also provide insights into the responses of the fish. For example, in the case of Todarodes pacificus, schooling behavior of anchovies varied based on the hunting behavior of the squid (Vijai et al. 2017). More generally, there is a need to increase the number of A. dux observations in the wild using ROVs (Remote Operational Vehicles) and/or manned submersibles. The Sea of Japan, the northern waters of the Iberian Peninsula, and the Canary Islands would be the most appropriate places. Due to the high economic cost and the complexity of these operations, research should be interdisciplinary and with the participation of researchers and facilities from several countries. The participation of media committed to the dissemination of wildlife has already proved very fruitful.

\section{ACKNOWLEDGMENTS}

We wish to acknowledge Luis Laria for his inestimable help handling the giant squid specimen and to Javier Onicol for the photographs. We are also grateful to the editor and two anonymous referees for their comments and suggestions, which greatly improved the original manuscript.

\section{Angel Guerra, ${ }^{1}$ Ángel F. González, And}

Graham J. Pierce

Manuscript received 27 July 2017; revised 6 October 2017; accepted 16 October 2017. Corresponding Editor: John Pastor.

Instituto de Investigaciones Marinas (CSIC), Eduardo Cabello 6, 36208 Vigo Spain.

${ }^{1}$ E-mail: angelguerra@iim.csic.es

Literature Citations are available as supporting information at: http://onlinelibrary.wiley.com/doi/10.1002/ecy.2073/suppinfo 